\title{
Psoriasis is an independent predictor of increased risk of allergic reaction during percutaneous coronary interventions. Big data analysis from the Polish National PCI Registry (ORPKI)
}

\author{
Zbigniew Siudak ${ }^{1}$, Kalina Wysocka-Dubielecka ${ }^{2}$, Krzysztof Malinowski ${ }^{3}$, \\ Artur Dziewierz ${ }^{4}$, Tomasz Tokarek ${ }^{4}$, Krzysztof Plens ${ }^{5}$, Dariusz Dudek ${ }^{4}$ \\ ${ }^{1}$ Faculty of Medicine and Health Science, Jan Kochanowski University, Kielce, Poland \\ ${ }^{2}$ Department of Dermatology, Szpital Miedzyleski, Warsaw, Poland \\ ${ }^{3}$ Institute of Public Health, Faculty of Health Sciences, \\ Jagiellonian University Medical College, Krakow, Poland \\ ${ }^{4} 2^{\text {nd }}$ Department of Cardiology, Jagiellonian University Medical College, Krakow, Poland \\ ${ }^{5}$ KCRI Ltd., Poland
}

\begin{abstract}
Background: The presence of psoriasis is currently considered by the European Society of Cardiology cardiovascular prevention guidelines of 2016 as one possible cardiovascular risk factor. Patients with psoriasis and concomitant coronary artery disease treated by means of percutaneous coronary intervention (PCI) are a fairly large subgroup of patients that have been usually omitted in mainstream research. The aim herein, was to identify the incidence of psoriasis, baseline characteristics and periprocedural outcome with a special focus on procedural complications in patients undergoing percutaneous coronary procedures.

Methods: All consecutive patients who had either coronary angiography or coronary angiography with immediate PCI in Poland in 2014 and 2015 were included. Patients were assigned to two groups based on previous diagnosis: with psoriasis and without psoriasis. Clinical outcome was defined as any periprocedural death.

Results: There were 405,078 patients included in this analysis. Psoriasis (moderate or severe) was diagnosed in 1507 (0.4\%) of them. Psoriasis was an independent predictor of allergic reaction occurrence (odds ratio [OR] 6.02; 95\% confidence interval [CI] 1.44-25.22; $p=0.014$ ). After propensity score adjustment, psoriasis remained a significant predictor of allergic reaction (OR 5, 95\% CI 1.2-20.7; $p=0.0245$ ). There were no differences in rates of periprocedural deaths in patients with or without psoriasis (death: $0.95 \%$ vs. $0.62 \%, p>0.05$ ).

Conclusions: Severe or moderate psoriasis is an independent risk factor for the occurrence of allergic reaction during percutaneous coronary procedures. There were no differences in periprocedural mortality and complications in patients with versus those without psoriasis. (Cardiol J 2020; 27, 3: 278-284) Key words: infarction, coronary, psoriasis, anaphylaxis
\end{abstract}

Address for correspondence: Assoc. Prof. Zbigniew Siudak MD, PhD, Faculty of Medicine and Health Science, Jan Kochanowski University, IX Wiekow Kielc 19, 25-317 Kielce, Poland, tel: +48 4134969 09, fax: +48 413496916 , e-mail: zbigniew.siudak@gmail.com

Received: 22.03.2018 Accepted: 7.07.2018 


\section{Introduction}

Psoriasis is a chronic autoimmune inflammatory disease, the prevalence of which ranges from $1.5 \%$ to $4.7 \%$ in the general population making it a significant healthcare issue [1-3]. The immunemediated inflammatory pathogenesis of psoriasis is linked to another inflammatory disease which is atherosclerosis $[4,5]$. The presence of psoriasis is currently considered by the European Society of Cardiology (ESC) cardiovascular prevention guidelines of 2016 as one possible cardiovascular risk factors within a wide group of autoimmune and inflammatory diseases [6]. Currently the American Heart Association (AHA) recommendations include risk factor screening in patients with psoriasis from as early as age 20 and by the age 40 a full list of these including various cardio-metabolic parameters need to be identified [7, 8]. Retrospective data concerning the effect of psoriasis on cardiovascular morbidity and mortality seem to confirm its adverse outcome on the occurrence of myocardial infarction or development of coronary artery disease, however, meta-analysis and literature reviews provide inconclusive data, probably because of confounding factors and the moderate quality of cardiovascular risk factor reporting (psoriasis) in large datasets [9-13]. In the Rotterdam study, authors did not find a correlation between mild psoriasis and risk for the development of cardiovascular events or atherosclerosis which seems to support the general consensus that if any, psoriasis may have its deleterious effect only if at least moderate or severe presentation is expressed [14]. A combined clinical endpoint of death, myocardial infarction and stroke was more frequent in patients with severe psoriasis than in those without, which is the only prospective observation available thus far $[15,16]$.

Patients with psoriasis and concomitant coronary artery disease treated by means of percutaneous coronary intervention (PCI) are a fairly large (in definite numbers) subgroup of patients that have usually been omitted in mainstream research.

The main aim of this analysis was to identify the incidence of psoriasis, baseline characteristics and periprocedural outcome with a special focus on procedural complications in this subgroup of patients.

\section{Methods}

The Polish National PCI database (ORPKI) is a registry (with eCRF) for all percutaneous coronary procedures that have been performed in Poland since 2004 and is currently operated by the Jagiellonian University Medical College in Krakow. Annual reports are published each year and the registry rationale has been described before [17, 18]. In this manuscript, data for the calendar year 2014 (January-December) and 2015 (January-December) were analyzed. All consecutive patients who had either coronary angiography or coronary angiography with immediate PCI in 155 interventional cardiology centers in Poland were included in this analysis. Patients with incomplete records concerning baseline characteristics were excluded. The reason for analyzing data from 2014 onwards was due to the fact that psoriasis was implemented for the first time into eCRF of the ORPKI database on January $1^{\text {st }}, 2014$.

Periprocedural mortality was defined as death from any cause during angiography/PCI. Psoriasis was defined as severe or moderate presentation as confirmed by prior diagnosis by a dermatologist (PASI index $>10$ ). Only moderate and severe presentations were taken into account since they have been proven to have an impact on cardiovascular disease $[6,11,13]$. Allergic reaction was defined as any hypersensitive response of the immune system presenting as: bronchospasm, asthma exacerbation, conjunctivitis, urticaria, eczema, angioedema, anaphylactic shock. All these symptoms had to be revealed during a patient stay at a catheterization laboratory and had not been present prior to admission.

Other complications or adverse events were diagnosed at the operator's discretion according to current ESC definitions. Clinical outcome was defined as any periprocedural death. No further evaluation or follow-up of patients was performed. All patients provided informed consent. The study complied with ethical principles for clinical research based on the Declaration of Helsinki with later amendments. No external funding was used to support this registry.

\section{Statistical analysis}

Categorical variables were presented as numbers and percentages. The distributions of continuous variables were expressed as mean \pm standard deviation (SD), standard error (SE), median with interquartile range (IQR). Additionally, the number of available cases and minimum and maximum values were also presented. Normality was assessed by the Lilliefor test. Equality of variances were assessed using the Levene test. Differences between groups were compared using the Stu- 
dent or Welch t-test depending on the equality of variances for normally distributed variables. The Mann-Whitney U test was used for non-normally distributed continuous variables. Categorical variables were compared with the Fisher exact test for the $2 \times 2$ tables or by the Pearson $\chi^{2}$ test for the other tables. P-values less than 0.05 were assumed to indicate statistical significance.

Simple logistic regression was used for each of potential factor as a predictor for occurrence of allergic reaction. Then if $p$-value for a specific factor was less than 0.2 such factor was introduced into multiple logistic regression. The recommendation for using a significance level as high as 0.20 or 0.25 as screening criterion for initial variable selection is based on work by Bendel and Afifi (1977) [19] on linear regression and on work by Mickey and Greenland (1989) [20] on logistic regression. Only significant predictors and potential confounders (for adjustment) remained in the final model. The same procedure was repeated considering correction for rare events [21]. Both models were diagnosed using receiver operating characteristic curve and area under curve parameter.

The propensity score for psoriasis was calculated based on diabetes, hypertension, smoking, clinical diagnosis, kidney disease, presence of multivessel disease glycoprotein inhibitor use, access site, contrast volume, radiation, age, weight and gender. Then the odds for allergic reaction were calculated using logistic regression with presence of psoriasis as a covariate and was conditioned on propensity score.

Analysis was performed in $\mathrm{JMP}^{\circledR}$ 9.0.0. (SAS Institute Inc., Cary, NC, 1989-2007) and R 3.3.0. (A language and environment for statistical computing. R Foundation for Statistical Computing, Vienna, Austria).

\section{Results}

There were 405,078 patients with full records in the ORPKI database for the period of January $1^{\text {st }} 2014$ till December $31^{\text {st }} 2015$ were included in this analysis. Psoriasis (moderate or severe) was diagnosed in $1507(0.4 \%)$ of them. Patient baseline and clinical characteristics are presented in Table 1. Procedural outcome as well as frequency of complications in patients with and without psoriasis are presented in Table 2 . The occurrence of periprocedural death, stroke and sudden cardiac arrest did not differ between the groups even though baseline and clinical characteristics in patients with psoriasis were high risk (significantly higher prevalence of diabetes, prior myocardial infarction, smoking and hypertension). Allergic reaction was more frequent during $\mathrm{PCI}$ in patients with psoriasis than in those without psoriasis $(0.08 \%$ vs. $0.41 \%$, $\mathrm{p}=0.0226$ ). There was no differences in the occurrence of periprocedural complications and death between the studied groups. Independent predictors of allergic reaction occurrence are presented in Table 3. Psoriasis was an independent predictor of allergic reaction occurrence (odds ratio [OR] 6.02; 95\% confidence interval [CI] 1.44-25.22; $\mathrm{p}=0.014)$. After propensity score adjustment psoriasis remained a significant predictor of allergic reaction (OR 5; 95\% CI 1.2-20.7, $\mathrm{p}=0.0245$ ). Model adjustment for logistic regression is presented in Figure 1.

\section{Discussion}

Since psoriasis usually presents for the first time in adolescents and young adults, it is a lifelong burden and has a possible impact for development of other comorbidities. Psoriatic arthritis may appear in up to $30 \%$ of patients leading to decreased mobility and thus permanent disability which is an adverse condition for primary prevention of cardiovascular disease, metabolic syndrome and insulin resistance in diabetes mellitus [12]. The present study has confirmed more aggravating past medical history, comorbidities and higher risk demographics for patients with diagnosed psoriasis who were scheduled for coronary angiography and or PCI, either elective or urgent one. Mild psoriasis accounts for approx. $60 \%$ of all cases. The overall frequency of psoriasis $(0.4 \%)$ was lower than in previous studies, however, the present focus was only on severe and moderate forms of psoriasis which have been documented to impact cardiovascular morbidity [11, 16, 22].

Recent coronary computed tomography studies revealed that patients with psoriasis had greater plaque burden and high risk plaque prevalence which was reduced at 1 year of observation following effective anti-inflammatory treatment which was revealing for the first time that such a correlation was observed [23]. Severe forms of psoriasis have also been named as a strong and independent predictor of ischemic stroke [24]. As previously observed, it seems that if any, psoriasis may have its deleterious effect only if it was at least expressed as moderate or severe presentation and this is the group which was under investigation herein. Even though patients with psoriasis in the registry were higher risk in- 
Table 1. Baseline demographic, clinical characteristic and procedure.

\begin{tabular}{|c|c|c|c|}
\hline Variable & $\begin{array}{l}\text { No psoriasis } \\
N=403,571\end{array}$ & $\begin{array}{l}\text { Psoriasis } \\
N=1507\end{array}$ & $\mathbf{P}$ \\
\hline Male gender & $250,127(62 \%)$ & $1041(69.1 \%)$ & $<0.0001$ \\
\hline Age & $66.3 \pm 10.9$ & $63.3 \pm 10.6$ & $<0.0001$ \\
\hline Diabetes & $90,043(22.3 \%)$ & $492(32.7 \%)$ & $<0.0001$ \\
\hline Prior MI & $91,235(22.6 \%)$ & $383(25.4 \%)$ & 0.01 \\
\hline Prior $\mathrm{PCl}$ & $102,131(25.3 \%)$ & $389(25.8 \%)$ & 0.656 \\
\hline Prior CABG & $23,406(5.8 \%)$ & $81(5.4 \%)$ & 0.508 \\
\hline Smoking - active & $68,486(17 \%)$ & $427(28.3 \%)$ & $<0.0001$ \\
\hline Hypertension & $284,271(70.4 \%)$ & $1129(74.9 \%)$ & 0.0001 \\
\hline Indication: & & & 0.0002 \\
\hline STEMI & $48317(11.9 \%)$ & $219(14.5 \%)$ & \\
\hline NSTEMI & $52864(13.1 \%)$ & $240(15.9 \%)$ & \\
\hline Unstable angina & $124,322(30.8 \%)$ & $440(29.2 \%)$ & \\
\hline Stable angina & $158,635(39.3 \%)$ & $542(35.9 \%)$ & \\
\hline Angiography only & $221,327(54.8 \%)$ & $767(50.9 \%)$ & 0.0022 \\
\hline Multivessel disease with or without LMCA involvement & $151,538(37.7 \%)$ & $643(42.8 \%)$ & $<0.0001$ \\
\hline P2Y12 during the procedure & $88,757(21.9 \%)$ & $397(26.3 \%)$ & 0.0002 \\
\hline UFH during $\mathrm{PCl}$ & $153,985(84.5 \%)$ & $644(87 \%)$ & 0.0595 \\
\hline LMWH during $\mathrm{PCl}$ & $5980(3.3 \%)$ & $25(3.4 \%)$ & 0.8361 \\
\hline GP Ilb/llla during $\mathrm{PCl}$ & $12,056(6.6 \%)$ & $68(9.2 \%)$ & 0.0075 \\
\hline Thrombolysis during $\mathrm{PCl}$ & $376(0.2 \%)$ & $1(0.1 \%)$ & 1.000 \\
\hline Contrast volume $[\mathrm{mL}]$ & $128 \pm 79$ & $135 \pm 83$ & $<0.0001$ \\
\hline Radiation dose [Gy] & $0.796 \pm 0.952$ & $0.957 \pm 1.227$ & $<0.0001$ \\
\hline
\end{tabular}

CABG — coronary artery bypass grafting surgery; GP — glycoprotein; Gy — Grey; LMCA — left main coronary artery; LMWH — low molecular weight heparin; MI - myocardial infarction; NSTEMI — non-ST-segment elevation myocardial infarction; PCI — percutaneous coronary intervention; STEMI — ST-segment elevation myocardial infarction; UFH — unfractionated heparin

Table 2. Clinical outcome and procedural complications.

\begin{tabular}{|c|c|c|c|}
\hline Variable & $\begin{array}{c}\text { No psoriasis } \\
N=182,244(\mathrm{PCl}) \\
N=221,327 \\
\text { (Angiography) }\end{array}$ & $\begin{array}{c}\text { Psoriasis } \\
\text { N = } 740(\mathrm{PCl}) \\
\mathbf{N}=767 \\
\text { (Angiography) }\end{array}$ & $\mathbf{P}$ \\
\hline Death during angiography & $172(0.08 \%)$ & $0(0 \%)$ & 1.000 \\
\hline Death during $\mathrm{PCl}$ & $983(0.54 \%)$ & $7(0.95 \%)$ & 0.128 \\
\hline SCA during angiography & $905(0.22 \%)$ & $7(0.46 \%)$ & 0.0901 \\
\hline SCA during $\mathrm{PCl}$ & $884(0.49 \%)$ & $6(0.81 \%)$ & 0.1818 \\
\hline Allergic reaction during angiography & $160(0.07 \%)$ & $0(0 \%)$ & 1.000 \\
\hline Allergic reaction during $\mathrm{PCl}$ & $145(0.08 \%)$ & $3(0.41 \%)$ & 0.0226 \\
\hline Stroke during angiography or $\mathrm{PCl}$ & $55(0.01 \%)$ & $0(0 \%)$ & 1.000 \\
\hline Coronary artery perforation during $\mathrm{PCl}$ & $295(0.16 \%)$ & $0(0 \%)$ & 0.6373 \\
\hline $\mathrm{Ml}$ during $\mathrm{PCl}$ & $173(0.09 \%)$ & $0(0 \%)$ & 1.000 \\
\hline No-reflow during $\mathrm{PCl}$ & $1062(0.58 \%)$ & $8(1.08 \%)$ & 0.0850 \\
\hline
\end{tabular}

$\mathrm{MI}$ - myocardial infarction; $\mathrm{PCl}$ - percutaneous coronary intervention; SCA — sudden cardiac arrest 
Table 3. Independent predictors of allergic reaction during angiography and/or percutaneous coronary intervention.

\begin{tabular}{lccc}
\hline Variable & OR & $95 \% \mathrm{Cl}$ & P \\
\hline Psoriasis & 6.02 & $1.44-25.22$ & 0.014 \\
Diabetes mellitus & 0.47 & $0.24-0.92$ & 0.026 \\
Hypertension & 0.57 & $0.36-0.89$ & 0.014 \\
STEMI/NSTEMI vs. other & 0.58 & $0.35-0.97$ & 0.036 \\
GP IIb/Illa inhibitors use & 4.56 & $2.74-7.59$ & $<0.001$ \\
log per 1 Gy (radiation dose) & 1.67 & $1.22-2.28$ & 0.001 \\
Male gender & 0.54 & $0.33-0.87$ & 0.012 \\
\hline
\end{tabular}

$\mathrm{Cl}$ - confidence interval; GP — glycoprotein; Gy - Grey; STEMI — ST-segment elevation myocardial infarction; NSTEMI - non-ST-segment elevation myocardial infarction; OR — odds ratio

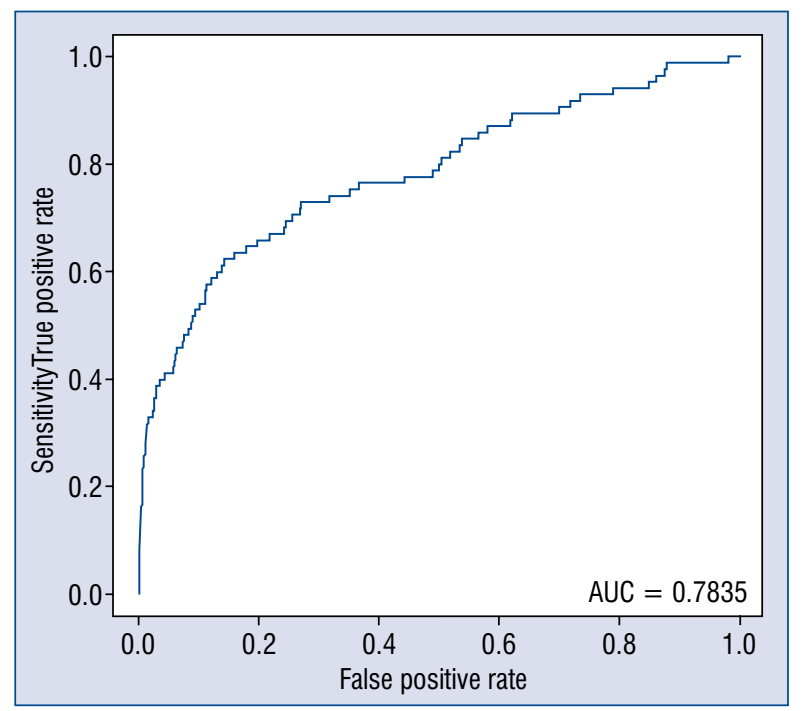

Figure 1. Model adjustment for logistic regression; AUC - area under curve.

dividuals with more frequent diabetes, hypertension and acute myocardial infarction (ST-segment elevation myocardial infarction, non-ST-segment elevation myocardial infarction) presentation as well as multivessel and more pronounced atherosclerosis, their immediate periprocedural individual outcomes like death, stroke or sudden cardiac arrest were similar to those without psoriasis $(<1 \%)$. Presently it is believed that this may stem from the fact that a majority of complications related to psoriasis, if any, occur at a later stage and may be recorded only if a longer follow up period is available and only in severe forms of psoriasis $[15,16]$. Adjusting for confounders, the presence of psoriasis does not seem to at least effect the periprocedural outcome of this group of patients.
The ORPKI database is one of the biggest datasets of consecutive patients with coronary artery disease treated invasively in European Union countries which continuously collects data on severe/moderate psoriasis occurrence since 2014. No previous studies with as large numbers of individuals as in the present registry ( $>400,000$ for a period of 2 consecutive calendar years) have been performed so far in investigating psoriasis as a comorbidity in the setting of PCIs. Big data analysis in this case helped identify interesting associations such as more frequently observed allergic reaction occurrence in patients with psoriasis than in those without, which has remained an independent predictor even after statistical adjustments. It is known that several factors may contribute to anaphylaxis or hypersensitivity reactions during percutaneous coronary procedures, namely acetylsalicylic acid, P2Y12, heparin, glycoprotein IIb/IIIa inhibitors and contrast use itself [25-28]. Stent platforms and polymers used in drug eluting stents may potentially induce such reactions as well $[29,30]$. In the present study a majority of all these variables were taken into consideration while performing multivariate analysis for independent predictors, however, not all were available in the database. The results indicate that glycoprotein $\mathrm{IIb} / \mathrm{III}$ inhibitor plays a significant role in allergic reaction occurrence as well as radiation doses which are a derivative of time of the procedure. It is worth noting that psoriasis conferred as the highest adjusted risk for allergic reaction even after propensity score adjustment. These findings need further investigation and suggest that caution should be used for patients presenting with severe or moderate forms of psoriasis when referred for invasive diagnostic and treatment. The results of the study may become hypotheses generating for 
future clinical studies. According to available research, this is the first report of such a relationship and requires further study.

\section{Limitations of the study}

The main limitation of this study is the nonrandomized design. Only periprocedural outcome could be provided which limits the observation and incidence of complications that appeared in periods after the procedure. Statistical measures were undertaken to compensate for possible biases like propensity score matching and multivariate analysis in order to identify independent predictors but since this is an observational study not all possible confounders may have been identified. An underreporting of psoriasis may be possible but only moderate or severe forms (which are less frequent in general population) were gathered in ORPKI Registry. Finally, the diagnosis of psoriasis (moderate or severe) was based on prior recognition by a physician and no additional data concerning its treatment or systemic complications were gathered in this registry.

\section{Conclusions}

Severe or moderate psoriasis is a rare comorbidity in patients undergoing percutaneous coronary procedures $(<1 \%)$. However, it is an independent risk factor for allergic reaction occurrence during percutaneous coronary procedures. The adjusted periprocedural mortality and complications rates were similar in those with psoriasis versus those without.

\section{Conflict of interest: None declared}

\section{References}

1. Gelfand JM, Mehta NN, Langan SM. Psoriasis and cardiovascular risk: strength in numbers, part II. J Invest Dermatol. 2011; 131(5): 1007-1010, doi: 10.1038/jid.2011.32, indexed in Pubmed: 21494241.

2. Gulliver W. Long-term prognosis in patients with psoriasis. Br J Dermatol. 2008; 159 Suppl 2: 2-9, doi: 10.1111/j.13652133.2008.08779.x, indexed in Pubmed: 18700909.

3. Schäfer T. Epidemiology of psoriasis. Review and the German perspective. Dermatology. 2006; 212(4): 327-337, doi: 10.1159/000092283, indexed in Pubmed: 16707882.

4. Hansson GK, Libby P. The immune response in atherosclerosis: a double-edged sword. Nat Rev Immunol. 2006; 6(7): 508-519, doi: 10.1038/nri1882, indexed in Pubmed: 16778830 .

5. Kremers HM, McEvoy MT, Dann FJ, et al. Heart disease in psoriasis. J Am Acad Dermatol. 2007; 57(2): 347-354, doi: 10.1016/j. jaad.2007.02.007, indexed in Pubmed: 17433490.
6. Piepoli M, Hoes A, Agewall S, et al. 2016 European Guidelines on cardiovascular disease prevention in clinical practice. The Sixth Joint Task Force of the European Society of Cardiology and Other Societies on Cardiovascular Disease Prevention in Clinical Practice (constituted by representatives of 10 societies and by invited experts) Developed with the special contribution of the European Association for Cardiovascular Prevention \& Rehabilitation (EACPR). Atherosclerosis. 2016; 252: 207-274, doi: 10.1016/j.atherosclerosis.2016.05.037.

7. Kimball AB, Gladman D, Gelfand JM, et al. National Psoriasis Foundation. National Psoriasis Foundation clinical consensus on psoriasis comorbidities and recommendations for screening. J Am Acad Dermatol. 2008; 58(6): 1031-1042, doi: 10.1016/j. jaad.2008.01.006, indexed in Pubmed: 18313171.

8. Jneid H, Anderson JL, Wright RS, et al. 2012 ACCF/AHA focused update of the guideline for the management of patients with unstable angina/non-ST-elevation myocardial infarction (updating the 2007 guideline and replacing the 2011 focused update): a report of the American College of Cardiology Foundation/ /American Heart Association Task Force on Practice Guidelines. J Am Coll Cardiol. 2012; 60: 645-681.

9. El-Mongy S, Fathy H, Abdelaziz A, et al. Subclinical atherosclerosis in patients with chronic psoriasis: a potential association. J Eur Acad Dermatol Venereol. 2010; 24(6): 661-666, doi: 10.1111/j.14683083.2009.03481.x, indexed in Pubmed: 19888942.

10. Ludwig RJ, Herzog C, Rostock A, et al. Psoriasis: a possible risk factor for development of coronary artery calcification. Br J Dermatol. 2007; 156(2): 271-276, doi: 10.1111/j.13652133.2006.07562.x, indexed in Pubmed: 17223866.

11. Ogdie A, Yu Y, Haynes K, et al. Risk of major cardiovascular events in patients with psoriatic arthritis, psoriasis and rheumatoid arthritis: a population-based cohort study. Ann Rheum Dis. 2015; 74(2): 326-332, doi: 10.1136/annrheumdis-2014-205675, indexed in Pubmed: 25351522.

12. Horreau C, Pouplard C, Brenaut E, et al. Cardiovascular morbidity and mortality in psoriasis and psoriatic arthritis: a systematic literature review. J Eur Acad Dermatol Venereol. 2013; 27 Suppl 3: 12-29, doi: 10.1111/jdv.12163, indexed in Pubmed: 23845149.

13. Armstrong EJ, Harskamp CT, Armstrong AW. Psoriasis and major adverse cardiovascular events: a systematic review and meta-analysis of observational studies. J Am Heart Assoc. 2013; 2(2): e000062, doi: 10.1161/JAHA.113.000062, indexed in Pubmed: 23557749.

14. Dowlatshahi EA, Kavousi M, Nijsten T, et al. Psoriasis is not associated with atherosclerosis and incident cardiovascular events: the Rotterdam Study. J Invest Dermatol. 2013; 133(10): 2347-2354, doi: 10.1038/jid.2013.131, indexed in Pubmed: 23492918.

15. Ahlehoff O, Lindhardsen J, Gislason GH, et al. Prognosis after percutaneous coronary intervention in patients with psoriasis: a cohort study using Danish nationwide registries. BMC Cardiovasc Disord. 2012; 12: 79, doi: 10.1186/1471-2261-12-79, indexed in Pubmed: 23006590.

16. Egeberg A, Thyssen JP, Jensen P, et al. Risk of myocardial infarction in patients with psoriasis and psoriatic arthritis: a nationwide cohort study. Acta Derm Venereol. 2017; 97(7): 819-824, doi: 10.2340/00015555-2657, indexed in Pubmed: 28350413.

17. Ochała A, Siudak Z, Legutko J, et al. Percutaneous interventions in cardiology in Poland in the year 2014. Summary report of the Association of Cardiovascular Interventions of the Polish Cardiac Society AISN PTK. Postepy Kardiol Interwencyjnej. 2015; 11(3): 177-181, doi: 10.5114/pwki.2015.54009, indexed in Pubmed: 26677356. 
18. Siudak Z, Tokarek T, Dziewierz A, et al. Reduced periprocedural mortality and bleeding rates of radial approach in ST-segment elevation myocardial infarction. Propensity score analysis of data from the ORPKI Polish National Registry. EuroIntervention. 2017; 13(7): 843-850, doi: 10.4244/EIJ-D-17-00078, indexed in Pubmed: 28606891.

19. Bendel R, Afifi AA. Comparison of stopping rules in forward “stepwise” regression. J Am Stat Ass. 1977; 72(357): 46-53, doi: 10.1080/01621459.1977.10479905.

20. Mickey RM, Greenland S. The impact of confounder selection criteria on effect estimation. Am J Epidemiol. 1989; 129(1): 125-137, doi: 10.1093/oxfordjournals.aje.a115101, indexed in Pubmed: 2910056.

21. Tomz M, King G, Zeng L. ReLogit: rare Events Logistic Regression. J Statistical Software. 2003; 8: 1-27.

22. Armstrong AW, Harskamp CT, Armstrong EJ. Psoriasis and metabolic syndrome: a systematic review and meta-analysis of observational studies. J Am Acad Dermatol. 2013; 68(4): 654-662, doi: 10.1016/j.jaad.2012.08.015, indexed in Pubmed: 23360868.

23. Lerman JB, Joshi AA, Chaturvedi A, et al. Coronary Plaque Characterization in Psoriasis Reveals High-Risk Features That Improve After Treatment in a Prospective Observational Study. Circulation. 2017; 136(3): 263-276, doi: 10.1161/CIRCULATIONAHA.116.026859, indexed in Pubmed: 28483812.

24. Gelfand JM, Dommasch ED, Shin DB, et al. The risk of stroke in patients with psoriasis. J Invest Dermatol. 2009; 129(10): 2411-2418, doi: 10.1038/jid.2009.112, indexed in Pubmed: 19458634.
25. Schiano P, Steg PG, Barbou F, et al. A strategy for addressing aspirin hypersensitivity in patients requiring urgent PCI. Eur Heart J Acute Cardiovasc Care. 2012; 1(1): 75-78, doi: 10.1177/2048872612441580, indexed in Pubmed: 24062892 .

26. Gollapudi RR, Teirstein PS, Stevenson DD, et al. Aspirin sensitivity: implications for patients with coronary artery disease. JAMA. 2004; 292(24): 3017-3023, doi: 10.1001/jama.292.24.3017, indexed in Pubmed: 15613671.

27. Juergens CP, Khaing AMi, McIntyre GJ, et al. Adverse reactions of low osmolar non-ionic and ionic contrast media when used together or separately during percutaneous coronary intervention. Heart Lung Circ. 2005; 14(3): 172-177, doi: 10.1016/j. hlc.2005.06.013, indexed in Pubmed: 16352273.

28. Hofmeier KS. Hypersensitivity reactions to modern antiplatelet and anticoagulant drugs. Allergo J Int. 2015; 24(2): 58-66, doi: 10.1007/s40629-015-0048-2, indexed in Pubmed: 26120548.

29. Montone RA, Sabato V, Sgueglia GA, et al. Inflammatory mechanisms of adverse reactions to drug-eluting stents. Curr Vasc Pharmacol. 2013; 11(4): 392-398, indexed in Pubmed: 23905634.

30. Kogias JS, Papadakis EX, Tsatiris CG, et al. Kounis syndrome: a manifestation of drug-eluting stent thrombosis associated with allergic reaction to contrast material. Int J Cardiol. 2010; 139(2): 206-209, doi: 10.1016/j.ijcard.2008.08.026, indexed in Pubmed: 18805597. 